\title{
Human Rights Violations against Rural Women Workers
}

\author{
Antony Jesu Rajan FSA. ${ }^{\# 1}$, Dr.R.Vettriselvan ${ }^{* 2}$, R.Divyaranjani ${ }^{* 3}$ \\ ${ }^{1}$ Assistant Lecturer, School of Commerce and Management Studies, DMI-St. Eugene University, Chipata, Zambia \\ ${ }^{2,3}$ Assistant Professor, AMET Business School, Academy of Maritime Education and Training, (AMET University), Chennai
}

\begin{abstract}
Most of the newspapers and periodicals publish about domestic and work place violence against women. Number of incidents were took part against women such as young brides being burnt for bringing 'insufficient' dowry, women dyeing in abnormal circumstances, rape on hapless women and molestation of young girls are of public protests by women activists and such protests receive media coverage. Very few women were escape death end up in their shelter homes, but the majorities were continues to live in their marital union and endure abusive behaviour from their relatives. This paper violence against women and some of the best practices being followed in the country to address the menace are being examined. It also highlights paper begins with profiling of Indian women with respect to a few selected socio economic indicators. It highlights the various dimensions of human rights violence against the women, especially culturally sanctioned forms of violence. It suggests best practices of combating violence against women. These causes may reflect the deep-rooted gender inequalities that prevail and persist against women in most of the Indian region. Many of the economic researchers were highlights that money is a matter for four functions such as a medium, a measure, a standard, a store. In fact, money has a multi-faceted role to play in a society. It is that medium by which all economic needs of human beings are fulfilled. Many human rights like right to work and right to equal wages for equal work have emerged from the economic needs of mankind.
\end{abstract}

Keywords — Human Rights; Women; Issues; Challenges; Strategies; Violations.

\section{Introduction}

Human Rights are a universal phenomenon because rights have been imbibed in our society over the years (Bunch, Charlotte. 1997). We are living in this earth as a human due to the existence of Human Rights (HR). Fundamental freedoms are based on mankind's demand for a life in which the inherent dignity and worth of each human being will receive respect and protection (Desai, Sonalde.1994). We have to respect and take care of the needs and rights of one another (Burns, John F.1998). Equality rights emphasise human rights despite:

- A different sex

- A different skin colour

- Speaking a different language

- Thinking different things

- Believing in different religions

- Owning more or less

- Being born in another social group

- Coming from another country

The prime aim of all societies and their governments is the fullest development of human personality. Live with the dignity is the fundamental rights of the every human being born in this world and its call as a Right to Live. The constant growth in the number and scope of human rights is the outcome of the concern of national and international organisations to secure to all human beings the right to live with dignity on this earth (Reardon, Geraldine.1995). All human beings should work in a cohesive manner, so that they develop a sense of belonging and identification with their society. Every person has the right to be a citizen of his/her country. This human right is a corollary to the basic human right to live in any part of his/her country and to enjoy all personal, social, political, economic and cultural freedoms. Also, through international conventions and laws, he/she can travel in any part of the world enjoying his/her basic human rights (Vettriselvan, R., Krishnan, S., \& Balakrishnan, A. 2013). Economic needs are vital for human survival and well being. In the modern society, most of the human needs are met by money; today money has become the fundamental need of a person. No transaction big or small can take place without the availability of money. In fact, money has a multi-faceted role to play in a society. It is that medium by which all economic needs of human beings are fulfilled. Many human rights like right to work and right to equal wages for equal work have emerged from the economic needs of mankind.

\section{Modern India Women}

The status of women in modern India is a sort of a paradox in many ways. If on one hand she is at the peak of ladder of success, on the other hand she is mutely suffering the violence afflicted on her by her own family members. When compared to the past modern women in India have achieved a lot and registered their success in the history but in reality they have to still travel a long way to achieve their equality. Their path is full of roadblocks and lot of obstacles. The women have left the secured domain of their home and are now in the battlefield of life, fully armoured with their talent (Krishnan, S., Vettriselvan, R., \& Tamilselvi, S. 2014). They had proven themselves in many

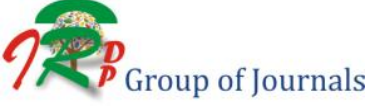


aspects in their respective fields. But, Indian women are yet to get their dues by the gender in many aspects especially in the workplace. In India there are 943 females per thousand males according to the census report of 2011, which is somehow better than the world average of 935 . This sex ratio of India clears that Indian society is still prejudiced against female gender. There are many problems against women in India which have to go through daily from their home, society and workplace (Omvedt, Gail.1990). These problems has become the part and partial of the life of many Indian women and also many of them were accepted this as their fate due to the discriminatory words from the society.

\section{Basic Rights for Women}

The Government has made effective provision for securing the right to work within the limits of its economic capacity and development, to education and to public assistance in the cases of unemployment, old age, sickness and disablement and in other cases of undeserved want to the public. There is an increasing number of women in the total workforce of countries of the world and the consequent emerging patterns of social interaction views the work place as a new domain of conflict in the 'running battle of the sexes' (Purushothaman, Sangeetha.1998). Small scale socio-economic surveys show that the women's occupational profile as well as the social mores and family values determine behavioural patterns specifically in the workplace.

Many survey results when interpreted denote that there is lot of sexual harassment and male-female relationship in the workplace. Working women's search for identity is also addressed in the context of the traditional pattern of gender and sexual exploitation.

\section{Women's Rights in Workplace}

The effects of the post 1990 economic liberalization era on the women workers in organised and unorganized sectors, recommended a legal strategy for empowerment of women. It emphasised the areas of concern and recommendations for legal interventions. Analysing on the issues affecting women workers with the advent of globalization, it emphasized a need for strict implementation of labour laws with particular emphasis on the unorganized workforce (Vettriselvan R., Sathya M., \& Balakrishnan A. 2014).

The National Human Rights Commission is the organization of its firm conviction and its belief they introduction of human rights syllabus leading to development of teachers training module on human rights concern would go a long way in setting the human rights culture not only in the school system but also in the young minds that are the future of the Indian nation.

\section{Right to Work}

- Everyone has the right to work.

- To free choice of employment.

- To just and favourable conditions of work and

- To protection against unemployment

- Right to assemble peacefully and without arms.

- Right to form unions and associations.

- Right to move freely throughout the territory of India.

- Right to reside and settle in any part of the territory of India

The Government has made effective provision for securing the right to work within the limits of its economic capacity and development, to education and to public assistance in the cases of unemployment, old age, sickness and disablement and in other cases of undeserved want to the public. Deaths of women are extreme outcome of ill treatment, psychological abuse, or physical violence suffered by women (Tinker, Anne.1996). On the other hand women were suffered by domestic violence on the regular basis in the form of psychological or physical abuse goes unreported. Very few women themselves file police cases against the ill treatment meted out to them due to societal barrier. Very few women were escape death end up in their shelter homes, but the majorities were continues to live in their marital union and endure abusive behaviour from their relatives.

Many attempts were made to address the issue of human rights violence against the women have been lopsided and short-sighted. The Dowry Prohibition Act, which was passed in the year 1961 and amended in 1984 and 1986, emphasizes the marital violence in the context of dowry related issues only. Inadequate dowry is the one of the underlying cause of domestic harassment against women among rural poor households, where dowry is either non-existent or is only a token payment for the marriage and there are other causes of abusive behavior against the innocent women. Immediate 'shortcomings' are negligence or failure to perform their duties expected of wives or daughter-in-law also leads violence. These causes were reflecting as deep-rooted gender inequalities that prevail and persist in most regions of India especially in rural.

Women were abused and made them vulnerable in this society due to all of these kinds of critical actions against the poor women by the high level of exploitation. These critical issues clearly had shown the poor status in the human development. Literacy, education and expectation of the life at birth and material well being are the major human development indices parameters shows very poor status in the overall situation of the nation. Rural areas its worth to mention that economic growths, growing urbanization, rise in per capita consumption and access to energy are the factors forcing the increase in the total demand for electricity are the few issues (Vettriselvan, R., 
Ruben Anto M., \& Jesu Rajan, FSA. 2018). In this situation, there is a susceptibility quotient, which is adverse to poverty reduction and sustainable development. Violence is committed on women both inside and outside her home. Domestic violence comprised of all the acts of intimidation and aggression which forces a woman to seek redresser by breaking the silence imposed on her by a patriarchal and hazardous culture. This operational meaning of domestic violence, however, does not include the culturally endorsed forms of violence (such as, uneven access to the household resources or other restrictions), except challenged by the women or others on her behalf. Minimally construed as the emotional, mental, physical and sexual abuse of a woman in her intimate relationship, such violence in the Indian circumstance includes intimidating acts by the members (both men and women) of her marital family. Often condoned by culture, such systemic violence enforces gender inequality by curtailing a woman's freedom and right to self-determination. In turn, the climate for violence is created by the prevailing disparities (on the basis of his/her gender) in an individual's entitlements to the family.

\section{Attacking the Roots of Violence (Preventive Measures)}

Through Intervention Strategies

- Identifying and monitoring vulnerable families to prevent violence.

- Creating new options by developing skills (selfconfidence, employment, political consciousness, etc.).

- Creating economic opportunities for women.

- Empowering women with the knowledge of their rights.

- Providing them with information about the various government welfare.

- Programmes and helping them to access them.

- Providing women with the necessary socio-cultural space to conceptualize and articulate their issues.

- Sensitizing the community and the bureaucracy to the issue of domestic.

- violence and its illegality.

- Media publicity given to the issue of domestic violence.

- Campaigning for gender just laws and reform in the criminal justice.

- Mechanism.

\section{Reacting to Instances/Issues of Domestic Violence}

\section{Through Theory Building}

- Documentation of cases and conceptualizing experiences.

- Systematically documenting the procedural lapses in the criminal justice system.
Through Intervention Strategies

- Extending material support to the women.

- Enabling her to access economic resources, information, etc.

- Shelter/short stay homes.

- Counselling.

- Medical aid/therapeutic assistance.

- Legal aid.

- Establishing support systems and monitoring cases of violence.

- Child care (hostels, foster care, schooling, etc.).

- Raising community/neighbourhood opinion against wife beating.

- Initiating collective community action against domestic violence.

- Mobilizing men and women from other mass-based groups, trade unions, etc.

- Garnering community support for the women survivors.

- Bringing community pressure on the perpetrators of violence to change their behaviour pattern and ensure the safety of the women in their marital home.

- Educating violent men to refrain from family violence

- Collaborating with the state agencies to provide adequate services to the victims.

- Training medical/legal and other personnel to respond adequately to the victim's needs/rights.

- Educating the police to develop new attitudes and skills in dealing with gender violence.

Further to empower women, many organizations are experimenting with innovative methods. They have experimented in forming local women's collectives. These collectives ensure that the agenda for action is locally determined. Furthermore, through effective networking between collectives, the individual local collectives are not isolated; they have the Confidence in the support of the collectives from the neighbouring villages. The way the organizations react to domestic violence that the inadequacies of the measures become evident. These inadequacies are largely due to the paucity of funds and the failure of the state to provide infrastructure (such as telephones, help lines, etc.) and the lack of support/referral services (such as shelter and childcare facilities).

There are no crisis centres providing women and children with protection against domestic violence, particularly in the night. They are unable to access state-run shelter homes without following lengthy procedures. These shelter homes are Spartan and unwelcoming. They do not have medical aid or other facilities to make women and children feel cared for and protected. Given the paucity of funds and infrastructure, voluntary organizations have devised many innovative strategies which are cost effective. They use local village/community councils to effect conciliation Women's collectives confront violent men and make them recognize that such behaviour is unacceptable. Recognizing the strength of collectives, these women's collectives have

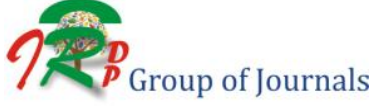


been able to enforce police action. In addition, organizations have collaborated with the National Commission for Women to speed up the settlement process through the women's courts.

\section{Violence against Women and Girls}

Opening the door on the subject of violence against the females in this world is like to be standing at the threshold of immense dark chamber vibrating with collective anguish, but with the sounds of protest throttled back to a murmur by the society. There should be an outrage against the women were aimed an intolerable status quo, instead denial, and the largely passive acceptance of 'the way things are.' Domestic violence against women by men is a worldwide phenomenon highlighted by number of researchers. Although not every woman has experienced this violence, and many expect not to face it, fear of violence is an important factor in the lives of most women in the world especially in the rural areas. These violence determines what they do, when they do it, where they do it, and with whom. Lack of participation of women in developmental activities and stay beyond the home are due to the fear of violence. Within the home also, women and girls were be subjected to physical and sexual abuse by the relatives as punishment or as culturally justified assaults in different ways. These acts shape their attitude to life, and their expectations of themselves.

\section{Conclusion}

Transforming the prevailing strategies for social discrimination against the women has become the top priority area, and must happen concurrently with increased direct action to rapidly improve the social and economic status of women in different aspects. As women earning more money from the economic activities has been repeatedly shown that they spend that more income in the further education and health of their children, as opposed to the counterpart, who often spend it on drink, tobacco or other women. As women raised their economic status, they will gain greater social standing in the family, household and the village, and will have greater voice in the society. As women gain influence in the field and consciousness on their work, they will make stronger claims to their entitlements gaining further training, better access to credit and higher incomes than the existing and command attention of police and courts when attacked by the counterpart. As women's economic power grows in the society will be helpful and easier to overcome the worst tradition of "son preference" and thus put an end to the evil of dowry system too. If son preference declines and acceptance of violence declines among the women, families will be more likely to educate more for their daughters, and age of marriage will rise and the child marriage will be eradicated. For every year beyond 4th grade that girls go to school, family size shrinks 20 percent, child deaths drop 10 percent and wages rise 20 percent. As women are better nourished and marry later, they will be healthier, more productive, and will give birth to healthier babies for the society and family. Only through action to remedy discrimination against women can the vision of India's independence an India where all people have the chance to live health and productive lives be realized by the proper gender sensitization.

\section{References}

[1] Bunch, Charlotte.,(1997) "The Intolerable Status Quo: Violence Against Women and Girls", The Progress of Nations, New York: UNICEF

[2] Burns, John F.,(1998), "Though Illegal, Child Marriage is Popular in Part of India" The New York Times. May 11.

[3] Desai, Sonalde.,(1994), "Gender Inequalities and Demographic Behavior: India", New York: The Population Council, Inc.

[4] Krishnan, S., Vettriselvan, R., \& Tamilselvi, S. (2014). Human Rights Violations in Unorganised Sectors- A Case of Dalits Labourers in Human Rights Violations, Edited by Dr.A.Balakrishnan, APH Publishing Corporation, New Delhi, 6069.

[5] Reardon, Geraldine.,(1995), Power and Process. Oxford: Oxfam

[6] Omvedt, Gail.,(1990), "Violence Against Women: New Movements and New Theories in India", Kali Primaries.

[7] Purushothaman, Sangeetha.,(1998). "The Empowerment of Women in India: Grassroots Women's Networks and the State", New Delhi: Sage Publications.

[8] Tinker, Anne.,(1996), "Improving Women's Health in India", Development in Practice Series. The World Bank

[9] Vettriselvan, R., Krishnan, S., \& Balakrishnan, A. (2013). Role of NGOs in Protect Human Rights for Dalits to Remove Social Exclusion- A Study in Inclusive Growth in India, Edited by Dr.S.Gurusamy, MJP Publishers, Chennai, 191-200.

[10] Vettriselvan R., Sathya M., \& Balakrishnan A. (2014). Human Resource Management Issues in Micro, Small and Medium Enterprises in Tamil Nadu in International Research Journal of Business and Management (IRJBM), VII(12):35-40 available at www.irjbm.org

[11] Vettriselvan, R., Ruben Anto M., \& Jesu Rajan, FSA. (2018). Rural Lighting for Energy Conservations and Sustainable Development, International Journal of Mech. Eng. and Tech. 9(7), 2018, pp. 604-611.

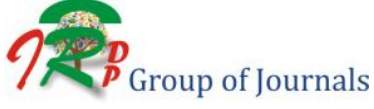

